MATEC Web of Conferences 37, 01040 (2015)

DOI: $10.1051 /$ matecconf $/ 20153701040$

(C) Owned by the authors, published by EDP Sciences, 2015

\title{
STATIC LOAD CHARACTERISTIC OF COMPLEX LOAD NODE WITH ALLOWANCE FOR AUTOMATION
}

\author{
Andrey Pazderin ${ }^{1}$, Alexander Tavlintsev ${ }^{\mathrm{a}}$ \\ ${ }^{1}$ Ural Federal University named after the first President of Russia B.N.Yeltsin, Ural Power Engineering Institute, \\ 620000 Ekaterinburg, Russia
}

\begin{abstract}
Identification of a load model is a sufficiently complicated and labour consuming task requiring work of a skilled expert. Increasing the degree of automation of information gaining about load reaction to modification of conditions of power supply will enable to accelerate and simplify solving the assigned task. The results of automaticexperimental data processing for solving the task of identification of the load model are presented in this paper.
\end{abstract}

\section{Introduction}

Mathematical model development for calculating steady-state conditions of a electrical network, inter alia, includes modeling electrical loads.

The concept "load characteristic" relates to the dependence of power consumption from parameters of operation conditions. The load characteristics exercise a decisive influence on modeling normal and emergency conditions of power systems. They should be accomplished for calculation of the steady-state conditions and determination of stability of power systems, solving the problem of frequency and load regulation, estimating efficiency of emergency control automatics, analysis of emergency processes and so on. At the same time the simplified load models or the standard static characteristics are used under network calculation. These models don't reflect the real interrelation between the condition parameters and the load value [1].

This paper concentrates on techniques of SLC identification (identification of the static load characteristics) for the purpose of further using the obtained load models to improve the mathematical model of a power system in the task of calculation of the steady-state conditions.

\section{Load models types}

A type of the equivalent load characteristic of a large consumer depends on the following factors: load structure (percentage of synchronous and induction motors, furnaces, lighting, domestic and rectifier load, etc.), operation mode of collectors, connecting circuit, parameters of input transformer, the availability of voltage control devices, power of compensating devices [2].

There are static load characteristics (SLC) and dynamic load characteristics (DLC).

a Corresponding author: winddaes@gmail.com

This is an Open Access article distributed under the terms of the Creative Commons Attribution License 4.0, which permits unrestricted use, distribution, and reproduction in any medium, provided the original work is properly cited. 
The static load characteristic by voltage is the dependence of active and reactive load power on the applied voltage in steady-state conditions $\mathrm{P}(\mathrm{U}), \mathrm{Q}(\mathrm{U})$ at a constant (rated, as a rule) frequency. For most large nodes of the power system, the static load characteristic by voltage is described by a quadratic polynomial [3-5]:

$$
P(U)=a_{0}+a_{1} \cdot U+a_{2} \cdot U^{2}
$$

or in relative units:

$$
P^{*}\left(U^{*}\right)=\left(b_{0}+b_{1} \cdot U^{*}+b_{2} \cdot\left(U^{*}\right)^{2}\right)
$$

\section{SLC identification}

In the course of this work an algorithm of the SLC identification with allowance for the above mentioned features of the dependence of $P(U)$ was developed. The algorithm is composed of a few modules, each of which solves a separate task in the framework of the SLC identification. So, the algorithm is easily complemented and it may be further modified. The software package "Matlab" has been chosen for computer realization of the developed solution. The algorithm of static load characteristic acquisition from archival data can be divided into the following stages:

1) Filtering the initial data.

2) Selection of intervals of constancy of the normal load power Determination of the SLM coefficients at the each interval of constancy of the rated load power.

3) Normalization of the coefficients.

4) Integration of the same static load characteristics.

5) Analysis and estimation of the obtained coefficients of the static load model.

The initial data are presented in Fig. 1. The data after filtering are presented in Fig. 2. Initially the arrays contained 491 pairs of measurements, after clustering they contain 13 pairs.

Execution of the testable algorithm gives the following results: Two intervals of constancy of load are selected on which the coefficients of the polynomial model are obtained:

on the voltage interval $3.42-3.68$ :

$a_{0}=71,2 ; a_{1}=-44,1 ; a_{2}=7,1 ;$

on the voltage interval $3.72-3.98$ :

$$
a_{0}=43,1 ; a_{1}=-31,1 ; a_{2}=5,5 ;
$$

The obtained result is presented in Fig. 3.

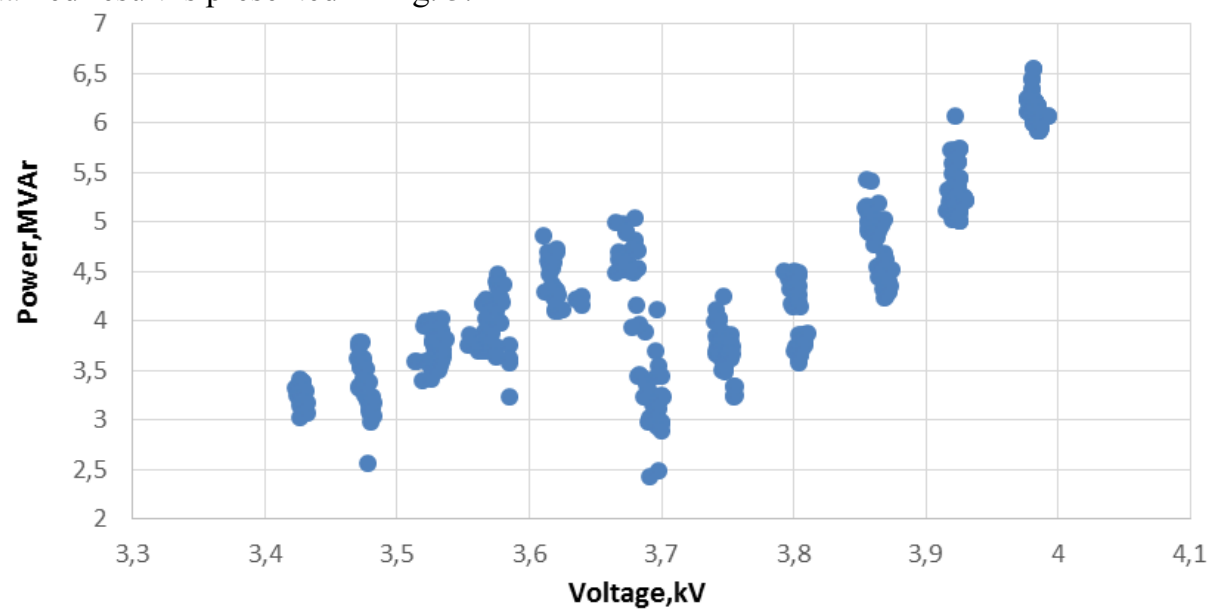

Figure 1. The initial data before filtering 


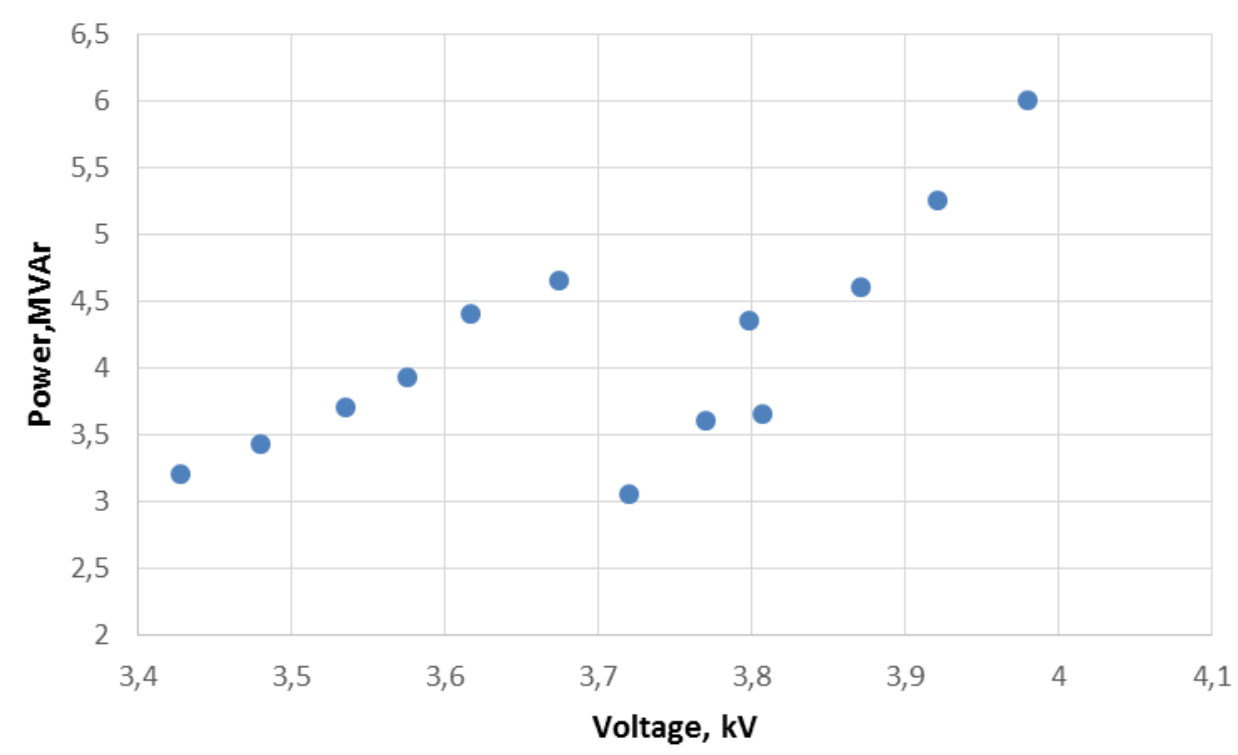

Figure 2. The initial data after filtering



Figure 3. The obtained static load characteristics in named units

It is necessary to choose the rated voltage for normalization of the coefficients. As in the previous case analysis of the available voltage shows that in the course of the experiment the phase voltage rather the than linear voltage was obtained. However, a part of measurements was obtained on far removed from the nearest voltage class voltage - in this connection it is preferably to use average voltage for each interval of constancy: $3.55 \mathrm{kV}$ for the first and 3.85 for the second Then, the rated power will be equal: $3.82 \mathrm{MVAr}$ for the static load characteristic obtained on the interval $3.42-3.68$ $(\mathrm{kV})(\mathrm{SLC} 1)$ and 4.44 MVAr for the static load characteristic obtained on the interval $3.72-3.98$ $(\mathrm{kV})(\mathrm{SLC} 2)$ So, the normalized coefficients of

$$
\begin{aligned}
& b_{0}=18,6 ; b_{1}=-40,9 ; b_{2}=2,3-\text { SLC } 1 ; \\
& b_{0}=9,7 ; b_{1}=-26,9 ; b_{2}=18,2 ;- \text { SLC } 2 .
\end{aligned}
$$

The static load characteristics in r.u. are presented in Fig. 4. 


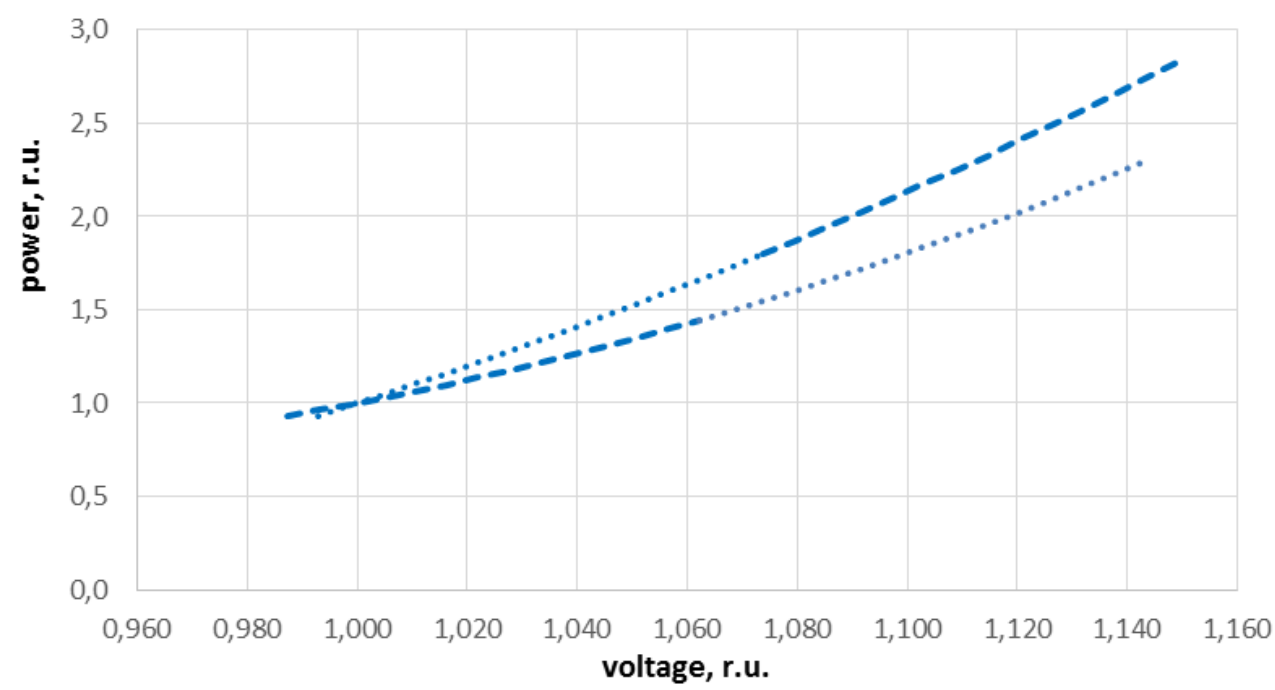

Figure 4. The obtained static load characteristics in relative units

Since the difference between the obtained parameters of the models is significant, the selected intervals of constancy of load relate to the different load characteristics and integration of the models is not performed.

Rejection of the ill-conditioned models does not influence the result because both obtained characteristics were built on the significant voltage range

Screening the characteristics with statistically insignificant parameters under the quantity of the obtained models is equal to 2 is not performed.

Similar to the previous paragraph it is necessary to calculate the regulating effect of load for estimation of the result. After that it will be compared with the tabular value.

For SLC 1 it is:

$$
\frac{\delta Q}{\delta U}\left(U=U_{\text {rated }}=1\right)=b_{1}+2 \cdot b_{2}=-40,9+2 \cdot 23,2=5,7
$$

for SLC 2:

$$
\frac{\delta Q}{\delta U}\left(U=U_{\text {rated }}=1\right)=b_{1}+2 \cdot b_{2}=-26,9+2 \cdot 18,2=9,5
$$

\section{Conclusion}

The value of $\delta Q / \delta U$ for industrial enterprises lies within the range of 3.2 - 6.4 [1,2]. The regulating effect of SLC1 lies in the mentioned range while the regulating effect of SLC 2 is greater than the upper limit of the range. This result shows that modeling load with the help of the standard models produces an significant error.

The developed technique of the SLC identification enables to obtain the parameters of the load models based on the measurement data. The developed algorithm is easily computer realized and may be modified. However, the obtained solution cannot be fully automated at this moment, because it requires attendance of an expert at some work stages (hypothesis advancement about the type of the model, analysis of the obtained results). The models obtained as a result of an application of the algorithm for test data processing shows its high efficiency. Real data processing doesn't enable to 
estimate accuracy of the algorithm, however, the preliminary estimate (calculation of the governing effect of load) also evidences about high accuracy of the SLC identification.

This work was financially supported by the Science Laboratory "Smart Grid" of the Ural Federal University, The program of competitiveness increase of UrFU and the Ministry of Education and Science of the Russian Federation (in the framework of state assignment).

\section{References}

1. K. Morison and H. Hamadani, IEEE Power Engineering Society General Meeting, 6, 408 (2006)

2. L. Hajagos and B. Danai, Laboratory Measurement of Modern Loads Subjected to Large Voltage Changes for Use in Voltage Stability Studies, (1996)

3. D. Karlsson and D. J. Hill, IEEE Transactions on Power Systems, 9 (1), 157 (1994)

4. J. L. Aguero, M. Beroqui, and S. Achilles, IEEE Power Engineering Society Summer Meeting. Conference Proceedings 2, 1330 (2009)

5. EPRI, Comprehensive Load Modeling for System Planning Studies, EPRI Product ID 1015999 (Palo Alto, USA, 2009). 